\title{
Change in Axial Length Pre and Post Cataract Surgery Measured with IOL Master
}

\section{Garcia Lopez, C}

http://hdl.handle.net/10026.1/5270

10.4172/2155-9570.1000544

Journal of Clinical \&amp; Experimental Ophthalmology

OMICS Publishing Group

All content in PEARL is protected by copyright law. Author manuscripts are made available in accordance with publisher policies. Please cite only the published version using the details provided on the item record or document. In the absence of an open licence (e.g. Creative Commons), permissions for further reuse of content should be sought from the publisher or author. 


\title{
Journal of Clinical \& Experimental Ophthalmology
}

\section{Change in Axial Length Pre and Post Cataract Surgery Measured with IOL Master}

\author{
Claudia García López ${ }^{1,2}$, Veronica García López ${ }^{1,2}$, Victoria de Juan ${ }^{2,3}$ and Raul Martin ${ }^{1,2,4^{*}}$ \\ ${ }^{1}$ Universidad de Valladolid, Instituto Universitario de Oftalmobiología Aplicada (IOBA), Paseo de Belén, 17 - Campus Miguel Delibes, 47011 Valladolid, España, Spain \\ ${ }^{2}$ Optometry Research Group, IOBA Eye Institute, School of Optometry, University of Valladolid. Valladolid, Spain \\ ${ }^{3}$ Department of Ophthalmology, Hospital Ramon y Cajal, 28034 Madrid, Spain \\ ${ }^{4}$ School of Health Professions, Plymouth University, Derriford Road, United Kingdom
}

*Corresponding author: Raul Martin, School of Health Professions, Peninsula Allied Health Centre, Plymouth University, Derriford Road, Plymouth PL6 8BH, United Kingdom, Tel: +44 (0)1752 587544; E-mail: raul.martin@plymouth.ac.uk

Received date: April 04, 2016; Accepted date: April 26, 2016; Published date: April 29, 2016

Copyright: ( 2016 López CG, et al. This is an open-access article distributed under the terms of the Creative Commons Attribution License, which permits unrestricted use, distribution, and reproduction in any medium, provided the original author and source are credited.

\begin{abstract}
Objective: Cataract surgery with intraocular lens (IOL) implantation tries to get a refractive result nearby to the optic emmetropia. So an accurate IOL power calculation is mandatory, and axial length (AL) measurement is one of the most influential parameter in this calculation. IOL Master is one of the most popular devices to measure AL, which uses the same group refractive index of the lens for all patients, independently of the cataract grade. But lens refractive index is higher as cataract grade increases. Nowadays cataract tends to be operated earlier, so moderate cataracts are the most extracted in clinical practice. Therefore, it is important to study the influence of moderate lens opacity in AL measurements. The objective of this study was to compare the AL value measures with IOL Master, before and after uncomplicated cataract surgery in patients with moderate cataracts.
\end{abstract}

Material and methods: This study included 153 eyes of 105 patients $(67.51 \pm 13.56$ years old) undergoing uncomplicated cataract surgery. Lens opacity was determined with the LOCSIII scale and AL was measured using optical biometry (IOL Master; Carl Zeiss Meditec) before and one month after intervention. Intraoperative measurements (ultrasound time and fluid volume) were also registered.

Results: Mean preoperative AL of $25.10 \pm 3.19 \mathrm{~mm}$ (range 20.54 to 36.06 ; IC95\% 24.59 to $25.60 \mathrm{~mm}$ ) and postoperative of $24.88 \pm 3.16 \mathrm{~mm}$ (IC $95 \% 24.37$ to 25.39 ; range 20.43 to $35.79 \mathrm{~mm}$ ). The mean AL difference before and after surgery was $0.19 \pm 0.05 \mathrm{~mm}(p=0.549$ ANOVA) with agreement limits from 0.09 to $0.29 \mathrm{~mm}$. It was observed more difference in eyes with larger AL $\left(r^{2}=0.14 p<0.01\right)$. The average cataract grade in each category was: nuclear opacity $2.25 \pm 1.00$ (range 1 to 5$)$ ( $p=0.564$ ANCOVA), cortical opacity $2.04 \pm 0.73$ (range 0 to 4 ) $(p=0.543$ ANCOVA), posterior subcapsular opacity $0.44 \pm 0.90$ (range 0 to 4$)(p=0.563$ ANCOVA), and nuclear color $2.40 \pm 1.05$ (range 0 to 5) ( $p=0.558$ ANCOVA), without statistical significant effect in the AL difference pre and after cataract surgery. The ultrasound time used during the surgery was $43 \pm 29$ seconds ( $p=0.525$ ANCOVA) and the fluid volume was $4.73 \pm 1.31$ ( $p=0.560$ ANCOVA) cubic centimeters without statistically significant relationship between these parameters and the difference in the AL measurement.

Conclusions: The difference in AL measurement with IOL Master before and after cataract surgery in eyes with low grade of cataract should be related with IOL Master reproducibility especially in extreme-long eyes. Moderate cataract showed non-statistically effect on AL measurement with IOL Master biometry.

Keywords: Cataract surgery; IOL master biometry

\section{Introduction}

Cataract surgery is one of the most frequently performed ophthalmic surgical procedures [1]. The last surgical techniques and the accurate devices that calculate the intraocular lens (IOL) power have made possible to achieve a good refractive outcome.

Nevertheless, a precise IOL calculation is not easy, depending on several parameters, such as axial length (AL) [2-6], anterior chamber depth [3,5], keratometry [2-5] or the lens formula [2-5]. Accurate AL measurement has been demonstrated to be the main factor for IOL power calculation [2-6], highlight related with the ocular biometry.
Optic biometry, based on the partial coherence interferometry (PCI), is one of the most performed techniques in the last years to $\mathrm{AL}$ measurement prior to cataract surgery [7] with accurate results [8-11].

However, it is necessary to take into account that PCI uses the same group (mean) refractive index of the crystalline lens for all cataract grades [11]. It seems that this group refractive index could vary with cataract grade, being higher as cataract grade increases [11]. For this reason, dense cataracts could induce a significant bias in AL value determined with PCI biometry or even fails the acquisition procedure $[2,6]$. Nevertheless, it is not entirely clear to what extent moderate cataracts affect AL measurements. Nowadays cataract tend to be operated earlier, so moderate cataract are the most extracted, while years ago it was more frequent to wait until the cataract was more 
Page 2 of 5

dense. For this reason, it is important to study the influence of moderate lens opacity in AL measurements.

The objective of this study was to compare the AL value measures with PCI biometry, before and 4 weeks after uncomplicated cataract surgery. This difference will be correlated with the type and intensity of cataract, evaluated with the Lens Opacities Classification System (LOCS III), and also with the time of ultrasound and fluid volume required in the surgery.

\section{Patients and Methods}

This was a prospective, comparative study that included the following visits: baseline (before cataract surgery), surgery day and one month (4 weeks) after surgical intervention. The first and the last visits were used to register the AL measures with IOL Master, and intraoperative measurements (ultrasound time and fluid volume) were recorded at the second visit. Also, for grading lens opacity the Lens Opacities Classification System (LOCS III) was used in the baseline visit.

\section{Subjects}

This study included 153 cataracts' eyes of 105 patients $(61.44 \%$ female) attending the IOBA-Eye Institute, University of Valladolid, Spain, scheduled to undergo phacoemusification surgery.

Patients with age-related cataract were included. Exclusion criteria included patients with significant pathology such as diabetic retinopathy, corneal dystrophy, past or present keratitis, corneal leucomas affecting the visual axis, corneal degenerations, corneal ectasias, or uveitis. Subjects with a history of eye surgery and those having combined procedures at the time of cataract surgery, and cases requiring surgical suturing or developing inflammation that did not correspond to the natural course of postoperative healing were also excluded.

After explaining the details of the study, written informed consent was obtained from all patients before enrolment. The study was approved by the Human Sciences Ethics Committee of the University of Valladolid and was carried out in accordance with the Declaration of Helsinki.

\section{Study visits}

An experimented optometrist performed the biometric AL measurement using PCI (IOL Master; Carl Zeiss Meditec, Dublin, Ireland) before and one month (4 weeks) after uncomplicated phacoemulsification cataract surgery. Post-surgery AL measurement was calculated taking into account the IOL material.

The same experienced ophthalmologist graded the lens opacity with the Lens Opacities Classification System (LOCS III) 12 in three main types of cataract: nuclear (range 1 to 6), cortical (range 1 to 5) and posterior subcapsular opacity (range 1 to 5 ). Also, nuclear color was graded (range 1 to 6 ).

The same experienced surgeon performed cataract surgery with IOL implantation (Acrysof natural IQ SN60WF, Alcon Cusí S. A. El Masnou, Barcelona, Spain when the IOL power was $>6.5 \mathrm{D}$, and Acrysof Multipiece MA60MA when the power was $<6.5 \mathrm{D})$. During the surgery ultrasound time and fluid volume were registered (Infiniti Vision System. Alcon Cusí S.A. El Masnou, Barcelona, Spain).

\section{Statistical analysis}

Statistical analysis was performed using the SPSS 14.0 (SPSS Chicago, Illinois, EEUU) statistical package for Windows.

The AL difference and limits of agreement were calculated using a Bland-Altman analysis, statistically difference pre and post cataract surgery was evaluated with an analysis of variance (ANOVA). P value $<0.05$ was considered statistically significant.

Differences in AL between each nuclear cataract grade were evaluated with an ANOVA with Games Howell post hoc correction. P value $<0.05$ was considered statistically significant. Linear regression was used to quantify the correlation between the AL difference pre and post-surgery with nuclear cataract (LOCS III), ultrasound time and fluid volume determining $\mathrm{r}^{2}$ coefficient.

The effect of grade (LOCS III) and type of cataract (nuclear, cortical, posterior subcapsular and nuclear color) and the ultrasound time and fluid volume in the difference between AL previous and after cataract surgery was evaluated with an ANCOVA (co-variance analysis). $\mathrm{P}$ value $<0.05$ was considered statistically significant.

\section{Results}

The average age was $67.51 \pm 13.56$ years (range 24 to 91) with a mean preoperative AL of $25.10 \pm 3.19 \mathrm{~mm}$ (range 20.54 to 36.06 ) (IC $95 \% 24.59$ to 25.60 ) and postoperative of $24.88 \pm 3.16 \mathrm{~mm}$ (IC95\% 24.37 to 25.39 ) (range 20.43 to 35.79 ).

The mean AL difference before and after surgery was $0.19 \pm 0.05$ $\mathrm{mm}$ ( $\mathrm{p}=0.549$ ANOVA) with agreement limits from 0.09 to $0.29 \mathrm{~mm}$. It was observed more difference in eyes with larger AL $\left(r^{2}=0.14 p<0.01\right)$ (Figure 1).

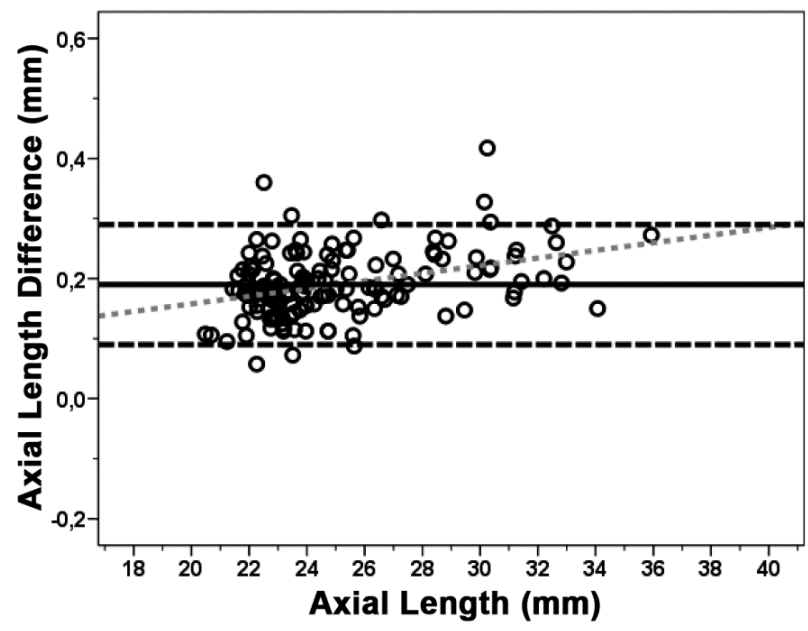

Figure 1: Bland-Altman plot of the axial length measurement before and after surgery.

The average cataract grade in each category was: nuclear opacity $2.25 \pm 1.00$ (range 1 to 5$)$ ( $\mathrm{p}=0.564$ ANCOVA), cortical opacity $2.04 \pm$ 0.73 (range 0 to 4$)$ ( $\mathrm{p}=0.543$ ANCOVA), posterior subcapsular opacity $0.44 \pm 0.90$ (range 0 to 4$)$ ( $\mathrm{p}=0.563$ ANCOVA), and nuclear color 2.40 \pm 1.05 (range 0 to 5$)(\mathrm{p}=0.558$ ANCOVA), without statistical significant effect in the AL difference pre and after cataract surgery. 
Severity of nuclear cataract was correlated with the difference in $\mathrm{AL}$. As observed in Figure 2 is found a similar difference for each nuclear cataract grade.

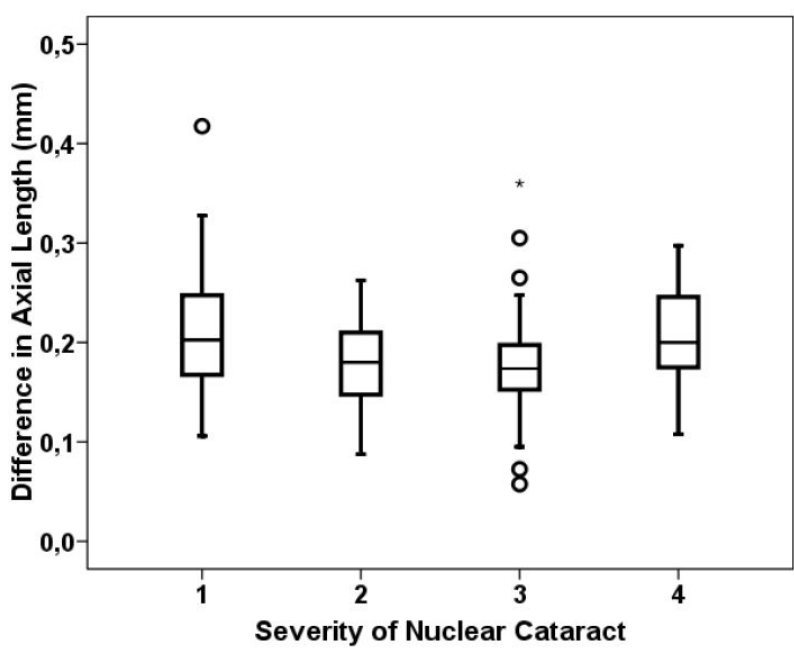

Figure 2: Box plots of difference (pre and post cataract surgery) in AL for severity of nuclear cataract according to the LOCS III grading scheme. Nuclear cataract grade 1 shows a difference of 0.20 \pm 0.06 ; grade $20.18 \pm 0.04$, grade $30.19 \pm 0.05$ and grade $40.21 \pm$ 0.05 ( $p>0.05$ ANOVA Games Howell). Non-significant correlation was found ( $\mathrm{r} 2=0.04, \mathrm{p}=0.446)$.

The ultrasound time used during the surgery was $43 \pm 29$ ( $\mathrm{p}=0.525$ ANCOVA) seconds and the fluid volume was $4.73 \pm 1.31(\mathrm{p}=0.560$ ANCOVA) cubic centimeters without statistically significant relationship between these parameters and the difference in the AL measurement (Figures 3 and 4).

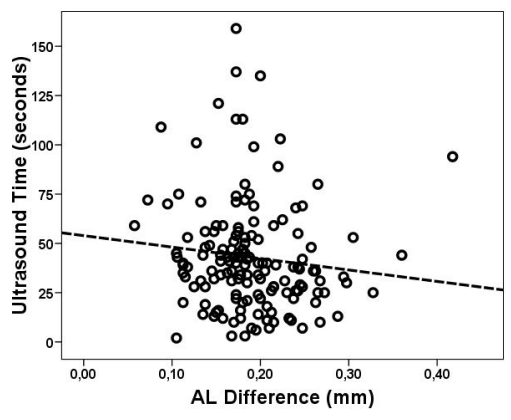

Figure 3: Linear regression between pre and post AL difference with ultrasound time used during the surgery $\left(\mathrm{r}^{2}<0.01, \mathrm{p}=0.177\right)$.

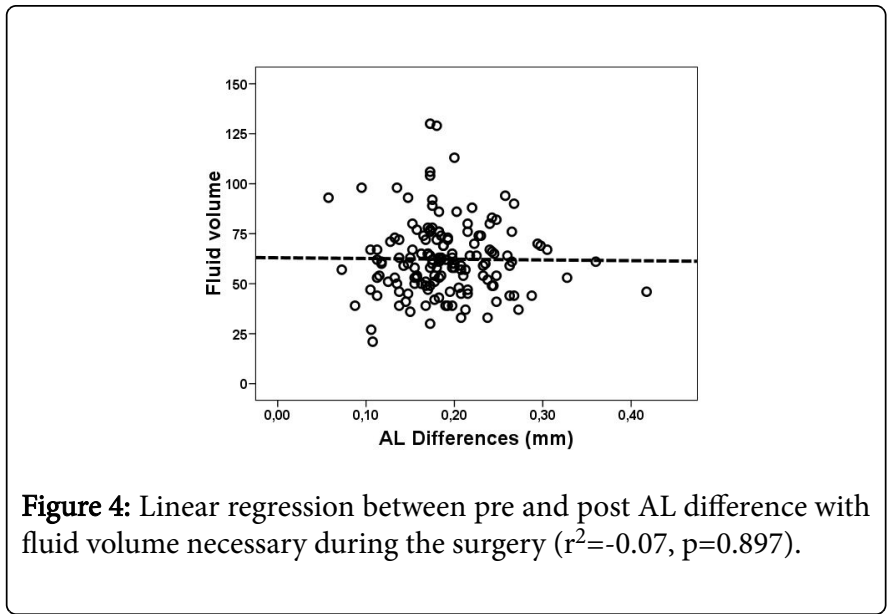

\section{Discussion}

This study shows that cataract grade of different type of cataract has no significant effect on the difference in the measurement of AL with IOLMaster. This find was previously reported by Prinz et al. [6], although this study found a weak correlation between nuclear cataract grade and the difference in AL $(r=-0.28, p=0.01)$. However, the difference in $\mathrm{AL}$ did not correlate with cortical or posterior subcapsular cataract.

Drexler et al. calculated the sum of nuclear color grade, opalescence grade, cortical grade and subcapsular grade (a score of 22 was the highest possible cataract grade) and detected a score of 12 that showed a significant correlation with the difference in $\mathrm{AL}(\mathrm{r}=0.32, \mathrm{p}<0.05)$ [11].

Prinz et al. found correlation between nuclear cataract grade and the difference in AL because they had a mean of $3.5 \pm 0.9$ (range 1 to 6 ), while in our study the average nuclear cataract grade was lower $(2.25 \pm 1.00$ range 1 to 5$)$, that is, they had more severe cataract than the present study [6].

Therefore, previous correlation between differences in AL with cataract grade could be related with high severity of the lens opacification.

Our results revealed a non-statistically significant difference between AL measured pre and post cataract surgery, agree with Prinz et al. results [6]. Nevertheless, other studies have found a statistically significant difference, which may be due to differences in the characteristics of the population studied [3,11-13].

Despite these differences, it should be noted that in the present study and in all aforementioned studies, a mean shortening of the eye postoperatively have been found (Table 1) [3,6,11-13].

If it is assumed that AL does not change with cataract surgery, it would be necessary to find a reason why systematically is found this shortening of the AL postoperatively. One reason proposed by Prinz et al. is that this error could be in the correction factors the IOLMaster uses for the pseudophakic AL, which are estimated for an average eye [6].

Another cause could be that crystalline lens refractive index change due to cataract [3,6]; the IOLMaster uses always the same group refractive index for all patients, and some authors have proposed an increase of this refractive index in order to minimize the AL difference 
$[6,11,13]$. We have found that moderate cataract grade has no significant effect on the difference in the AL measurement, so we think the difference found in our study is not related with the degree of cataract.

Chang et al. thought that accuracy of $\mathrm{AL}$ measurement in pseudophakic eyes could be affected by the IOLs chromophore [2]. To demonstrate it, in their study they used IOLs with and without blue blocker, and they found that there were no differences in preoperative and postoperative AL between this two types of IOLs. In our study, we could not test this theory, since the two types of the IOLs had blue light filter.

Also, to analyze the difference in $\mathrm{AL}$ is necessary to take into account the reproducibility of the IOLMaster. Shammas et al. performed measurements with this device with an interval of one month between them, finding a reproducibility of $0.01 \mathrm{~mm}$ [8]. It is observed that the difference of $0.19 \mathrm{~mm}$ found in our study is much greater than the reproducibility of IOLMaster, making necessary to find another cause for this difference.

In the present study, it is necessary to highlight that we have found a weak but significant correlation between $\mathrm{AL}$ and the before and after $\mathrm{AL}$ difference; it was observed more difference in eyes with larger AL. This tendency can also be observed in previous reports [6].

Comparing the data of our population with those of other papers (Table 1), our study included extreme-long eyes, and it should be noted that our study found the major difference between $\mathrm{AL}$ measured pre and post cataract surgery. We believe that AL difference before and after uncomplicated cataract surgery could be related with IOL Master reproducibility in extreme-long eyes.

\begin{tabular}{|l|l|l|l|l|l|}
\hline & $\begin{array}{l}\text { AL pre } \\
\text { (mean } \pm \text { SD) } \mathbf{m m}\end{array}$ & $\begin{array}{l}\text { AL-range pre } \\
\text { (mm to } \mathbf{m m} \text { ) }\end{array}$ & $\begin{array}{l}\text { AL post } \\
\text { (mean } \pm \text { SD) } \mathbf{m m}\end{array}$ & $\begin{array}{l}\text { AL-range post } \\
\text { (mm to } \mathbf{m m} \text { ) }\end{array}$ & $\begin{array}{l}\text { AL difference } \\
\text { (mean } \pm \text { SD) } \mathbf{m m}\end{array}$ \\
\hline Our study & $25.10 \pm 3.19$ & 20.54 to 36.06 & $24.88 \pm 3.16$ & 20.43 to 35.79 & $0.19 \pm 0.05$ \\
\hline$[6]$ & $23.47 \pm 1.15$ & 20.57 to 27.43 & $23.39 \pm 1.15$ & 20.39 to 27.39 & $0.07 \pm 0.05$ \\
\hline$[11]$ & $23.49 \pm 1.31$ & 20.46 to 27.88 & - & - & $0.12 \pm 0.06$ \\
\hline$[13]$ & $23.65 \pm 1.25$ & 18.96 to 29.02 & $23.57 \pm 1.26$ & 18.84 to 28.90 & $0.08 \pm 0.12$ \\
\hline$[3]$ & $23.47 \pm 1.10$ & 20.00 to 27.60 & $23.35 \pm 1.10$ & - & $0.13 \pm 0.13$ \\
\hline
\end{tabular}

Table 1: Comparative data of various studies.

It is necessary to evaluate the clinical impact of the difference between preoperative and postoperative AL measurements found in the present study. A measurement error in $\mathrm{AL}$ of $0.10 \mathrm{~mm}$ corresponds to approximately 0.28 diopters (D) [9,11]. In our study, this equivalence results in a refractive error of about $0.53 \mathrm{D}$. As the intraocular lens power goes in $0.50 \mathrm{D}$ steps for the SN60WF model, and $1.00 \mathrm{D}$ steps for the MA60MA model, we consider the difference found in this study is not clinically significant.

Neither ultrasound time nor fluid volume used had a statistically significant relationship with the difference in the AL measured. Prinz et al. found a weak correlation $(\mathrm{r}=-0.165, \mathrm{p}=0.04)$ between ultrasound time and the difference in the AL measurement [6]. To our knowledge, other studies have not analyzed the fluid volume influence.

The main limitation of this study could be related with number and characteristics of the patients and studies with sample size, similar number of short, medium and larger eyes and similar group of type and degree of cataract could be necessaries. However, conduct a study involving all these variables could be difficult to do so the results of this study could be of interest to cataract surgeons and biometry technicians that conduct IOLMaster Biometry in different range of patients.

In conclusion, the difference in AL measurement with IOL Master before and after uncomplicated phacoemulsification in eyes with low grade of cataract should be related with IOLMaster reproducibility especially in extreme-long eyes.

\section{Acknowledgement}

Authors want to thanks Dr. Herreras Cantalapiedra his help during this project.

\section{References}

1. Acosta R, Hoffmeister L, Román R, Comas M, Castilla M, et al. (2006) Systematic review of population-based studies of the prevalence of cataracts. Arch Soc Esp Oftalmol 81: 509-516.

2. Chang SW, Yu CY, Chen DP (2009) Comparison of intraocular lens power calculation by the IOLMaster in phakic and eyes with hydrophobic acrylic lenses. Ophthalmology 116: 1336-1342.

3. Rajan MS, Keilhorn I, Bell JA (2002) Partial coherence laser interferometry vs conventional ultrasound biometry in intraocular lens power calculations. Eye (Lond) 16: 552-556.

4. Eleftheriadis H (2003) IOLMaster biometry: refractive results of 100 consecutive cases. Br J Ophthalmol 87: 960-963.

5. Raymond S, Favilla I, Santamaria L (2009) Comparing ultrasound biometry with partial coherence interferometry for intraocular lens power calculations: a randomized study. Invest Ophthalmol Vis Sci 50: 2547-2552.

6. Prinz A, Neumayer T, Buehl W, Kiss B, Sacu S, et al. (2006) Influence of severity of nuclear cataract on optical biometry. J Cataract Refract Surg 32: 1161-1165.

7. Greenberg PB, Havnaer A, Oetting TA, Garcia-Ferrer FJ (2012) Cataract surgery practice patterns in the United States Veterans Health Administration. J Cataract Refract Surg 38: 705-709.

8. Shammas HJ, Chan S (2010) Precision of biometry, keratometry, and refractive measurements with a partial coherence interferometrykeratometry device. J Cataract Refract Surg 36: 1474-1478.

9. Findl O, Kriechbaum K, Sacu S, Kiss B, Polak K, et al. (2003) Influence of operator experience on the performance of ultrasound biometry compared to optical biometry before cataract surgery. J Cataract Refract Surg 29: 1950-1955.

10. Vogel A, Dick HB, Krummenauer F (2001) Reproducibility of optical biometry using partial coherence interferometry: intraobserver and interobserver reliability. J Cataract Refract Surg 27: 1961-1968. 
Citation: López CG, López VG, Juan V, Martin R (2016) Change in Axial Length Pre and Post Cataract Surgery Measured with IOL Master. J Clin Exp Ophthalmol 7: 544. doi:10.4172/2155-9570.1000544

Page 5 of 5

11. Drexler W, Findl O, Menapace R, Rainer G, Vass C, et al. (1998) Partial coherence interferometry: a novel approach to biometry in cataract surgery. Am J Ophthalmol 126: 524-534.

12. Chylack LT Jr, Wolfe JK, Singer DM, Leske MC, Bullimore MA, et al. (1993) The Lens Opacities Classification System III. The Longitudinal Study of Cataract Study Group. Arch Ophthalmol 111: 831-836.
13. Olsen T, Thorwest M (2005) Calibration of axial length measurements with the Zeiss IOLMaster. J Cataract Refract Surg 31: 1345-1350. 